\title{
Recria de Bovinos Nelore em Pastos de Brachiaria brizantha com Suplementação Protéica ou com Acesso a Banco de Proteína de Leucaena lecocephala. Características de Fermentação Ruminal ${ }^{1,2}$
}

\author{
Marcelo de Queiroz Manella ${ }^{3}$, Antônio João Lourenço ${ }^{4}$, Paulo Roberto Leme ${ }^{5}$
}

\begin{abstract}
RESUMO - Foram avaliadas as características de fermentação ruminal de bovinos Nelore com peso médio inicial de $152 \mathrm{~kg}$, submetidos durante 314 dias aos seguintes tratamentos: pastos de Brachiaria brizantha exclusiva (Teste), pasto de Brachiaria mais suplementação durante o período de seca (Seca), pasto de Brachiaria mais suplementação na seca e águas (Ano) ou pasto de Brachiaria com acesso a banco de Leucaena (Banco). O delineamento experimental foi o de blocos ao acaso com quatro repetições. O suplemento fornecido na seca continha 46,9\% de PB e o das águas, 43,9\% PB. As coletas de líquido ruminal foram realizadas em agosto, novembro, fevereiro e maio de três animais aleatórios de cada parcela. As porcentagens molares de propionato foram maiores para os animais suplementados, sendo que em agosto foi maior para os tratamentos Ano e Seca; nos outros períodos os animais do tratamento Ano apresentaram as maiores proporções. Similarmente, a relação acetato:propionato diminui nos tratamentos com suplemento em todas épocas. Houve interação dos valores de $\mathrm{N}_{-} \mathrm{NH}_{3}$ entre época do ano e tratamento, sendo que os animais suplementados apresentaram concentração mais elevada em agosto (Ano e Seca), fevereiro e maio (Ano). Houve também interação entre época do ano e tratamento para N-uréia, em que os tratamentos suplementados apresentaram valores mais elevados em agosto (Ano e Seca), fevereiro e maio (Ano) que os demais tratamentos e, em novembro, o Ano foi maior apenas no tratamento Teste.
\end{abstract}

Palavras-chave: ácidos graxos voláteis, bovinos de corte, fermentação ruminal, nitrogênio amoniacal, suplemento, pastejo, uréia sérica

\section{Post-Weaning Performance of Nelore Cattle Grazing Brachiaria brizantha with Proteic Supplement or Free Access to a Protein Bank of Leucaena leucocephala. Ruminal Fermentation Characteristics}

\begin{abstract}
The rumen fermentative characteristics of Nelore steers grazing Brachiaria Brizantha pastures (Teste), or supplemented during the dry season (Seca), dry and wet seasons (Ano) or with free access to a Leucaena bank (Banco), in a randomized block design with four replications, were evaluated. The dry season supplement had $46.9 \% \mathrm{CP}, 70 \%$ rumen degradable, and the wet season supplement, $43.9 \% \mathrm{CP}, 60 \%$ degradable. Rumen liquor was collected on August, November, February and May. The molar proportions of propionic acid in the supplemented animals were higher in August in the Ano and Seca treatment, and in the others periods animals in the treatment Ano had greater proportions. Similarly, the acetate:propianate ratio was lower in the supplemented treatments in all periods. The values of $\mathrm{N}-\mathrm{NH}_{3}$ showed an interaction between period and treatment, with the animals receiving proteic supplement showing higher values in August (Ano and Seca), February and May (Ano. Urea nitrogen showed an interaction between period and treatment, with supplemented animals showing higher values in August (Ano and Seca), February and May (Ano) than the other treatments, and in November the Ano treatment was higher than Teste only.
\end{abstract}

Key Words: beef cattle, feed supplement, grazing, rumen fermentation, rumen amonia nitrogen, urea nitrogen, volatile fatty acids

\section{Introdução}

A suplementação protéica de animais em pastejo é uma ferramenta que permite adequar a dieta, melhorar a conversão alimentar e o ganho de peso vivo, e, por conseqüência, diminuir o ciclo da pecuária de corte. Este suplemento deve ser capaz de propiciar um ambiente ruminal adequado para que a fermenta- ção ruminal seja a mais eficiente possível.

A suplementação com concentrado protéico altera alguns parâmetros ruminais, como a concentração de compostos nitrogenados amoniacais $\left(\mathrm{N}^{\left.-\mathrm{NH}_{3}\right)}\right.$ e os ácidos graxos voláteis (AGV's). O aumento de $\mathrm{N}-\mathrm{NH}_{3}$ favorece a otimização da síntese de proteína microbiana e melhora a digestibilidade da fibra (Satter \& Roffler ,1979). Os AGV's são as principais fontes

\footnotetext{
1 Trabalho financiado pela Fapesp.

2 Parte da dissertação de mestrado do primeiro autor.

${ }^{3}$ Bolsista da Fapesp. E.mail: manella@esalq.usp.br

${ }^{4}$ PQC VI do Instituto de Zootecnia, Nova Odessa, SP. E.mail: ajlourenco@izsp.br

5 Professor Doutor da FZEA-USP, Pirassununga, SP. E.mail: prleme@usp.br
} 
metabólicas de energia para os ruminantes, e suas concentrações totais, bem como as suas proporções relativas, podem ser alteradas com o fornecimento de suplementos protéicos e/ou energéticos (Baldwin, 1998; Olson et al., 1999).

Os produtos da fermentação ruminal diferem entre os alimentos, pois os microrganismos têm maior especificidade em digerir determinados nutrientes da dieta. Assim, dietas ricas em forragens resultam em maior atividade de bactérias celulolíticas e sacarolíticas, e a produção de ácido acético é maior. Por outro lado, com dietas ricas em amido e ou proteína, há, preferencialmente, maior ação das bactérias amilolíticas e ou proteolíticas, que por sua fez são produtoras de ácido propiônico (Church, 1988).

A concentração de $\mathrm{N}-\mathrm{NH}_{3}$ no rúmen depende da degradabilidade da fonte protéica utilizada e do equilíbrio entre sua produção e utilização pelos microrganismos. Para a otimização da produção de proteína microbiana é necessária a sincronização entre a disponibilidade de energia e compostos nitrogenados no ambiente ruminal (Firkins, 1996), desta forma a concentração de $\mathrm{N}-\mathrm{NH}_{3}$ no rúmen depende, entre outros fatores, da disponibilidade de carboidratos (Satter e Roffler, 1979, Nocek e Russel, 1988).

Segundo Church (1988), a maioria das bactérias são capazes de usarem o N-NH${ }_{3}$ como única fonte de nitrogênio, portanto, é necessário que a dieta promova concentrações adequadas no rúmen para a ótima atividade microbiana. Satter e Roffler (1979) e Slyter et al. (1979) afirmaram que para a otimização do crescimento e atividade microbiana as concentrações ruminais devem estar entre 2,0 e $5,0 \mathrm{mg} / \mathrm{dL}$.

O objetivo do trabalho foi avaliar as características da fermentação ruminal de bovinos Nelore com diferentes estratégias de recriada a pasto, recebendo suplementação alimentar protéica ou com livre acesso ao banco de proteína de Leucaena leucocephala.

\section{Material e Métodos}

O trabalho foi realizado na Estação Experimental Central, do Instituto de Zootecnia, localizado no município de Nova Odessa, SP. A área experimental utilizada era formada por 48 piquetes de 1 hectare cada, formando 16 parcelas experimentais divididas em três piquetes. O pastejo foi rotacionado dentro da parcela, com período de descanso e ocupação foi de 42 e 21, respectivamente. O delineamento experimental foi de blocos casualizados, com quatro tratamentos e quatro repetições.

Os animais foram submetidos aos seguintes tratamentos: pastagem exclusiva de Brachiaria brizanta (Teste); pastagem de Brachiaria brizanta associada a uma área adjacente (banco de proteína) com livre acesso a Leucaena leucocephala (Banco); Pastagem de Brachiaria brizanta + suplementação alimentar fornecida no cocho apenas período da seca (junho a novembro de 1998) (Seca); pastagem de Brachiaria brizanta + suplementação alimentar fornecida no cocho no período da seca e das águas (junho 1998 a maio de 1999) (Ano).

A pastagem utilizada foi formada de Brachiaria brizantha $c v$. Marandu, e o banco de proteína de Leucaena leucocephala $c v$. Cunnigaham, representando $25 \%$ da área do piquete. Foi realizada adubação de manutenção com $100 \mathrm{~kg} \mathrm{P}_{2} \mathrm{O}_{5} /$ ha e $60 \mathrm{~kg} \mathrm{~K}_{2} \mathrm{O} / \mathrm{ha}$, por cobertura e a lanço $100 \mathrm{~kg} \mathrm{~N} / \mathrm{ha}$ (500 kg de sulfato de amônio/ ha), em abril de 1998 e março de 1999.

O período da seca considerado durou 140 dias (25 de junho de 1998 a 12 de novembro 1999) e o das águas 174 dias (12 de novembro de 1998 a 4 de maio de 1999), sendo o período experimental total de 314 dias. Os dados relativos a pluviosidade e temperaturas estão descritos em Manella et al. (2002).

A disponibilidade de forragem foi estimada pelo método do quadrado $(1,0 \times 1,0 \mathrm{~m})$, e a avaliação das áreas de Leucaena leucocephala foi feita segundo Lourenço et al. (1981), em cinco pontos aleatórios das áreas avaliadas. Foram determinadas a matéria seca a $105^{\circ} \mathrm{C}$, a proteína bruta (PB) pelo método micro Kjeldahl (A.O.A.C.,1990), a digestibilidade $\ddot{i n}$ vitro (Tiley \& Terry, 1963), a fibra detergente neutro (FDN) e fibra detergente ácido (FDA; Robertson \& Van Soest, 1981).

Foram utilizados 192 bovinos machos inteiros da raça Nelore, recém desmamados, pesando em média $152 \mathrm{~kg}$ de peso vivo. A carga animal média foi de 683 $\mathrm{kg}$ peso vivo/ha (12 animais/parcela) no período da seca, e de $1182 \mathrm{~kg}$ de peso vivo/ha (14 animais/ parcela) no período das águas. A carga animal foi ajustada para que ao final de cada período de pastejo o piquete apresentasse o mínimo de $1500 \mathrm{~kg}$ de MS/ha. As pesagens individuais dos animais foram feitas com auxílio de balança eletrônica em intervalos de 28 dias, sempre pelo período da manhã sem jejum (Manella et al., 2002).

Constam na Tabela 1 os ingredientes utilizados na

R. Bras. Zootec., v.32, n.4, p.1002-1012, 2003 
composição do suplemento alimentar para os períodos das secas e águas e na Tabela 2, a composição química dos suplementos. Utilizaram-se $6,8 \%$ de sal e $0,16 \%$ de Rumensin ${ }^{\circledR}$ (monensina) no suplemento para limitar o consumo em aproximadamente $600 \mathrm{~g} /$ animal/dia. O suplemento foi fornecido a cada três dias em cocho coberto, sendo que as quantidades eram ajustadas em função das sobras do concentrado cocho.

As colheitas foram feitas nos meses de agosto/ 1998 (inverno), novembro/1998 (primavera), fevereiro/1999 (verão) e maio/1999 (outono), em 3 animais, sorteados ao acaso em cada parcela experimental, perfazendo um total de 48 animais por período de colheita. Foram colhidos aproximadamente $500 \mathrm{ml}$ de líquido ruminal através de sonda flexível oro-gástrica, e as amostras de sangue foram coletadas por venopunção da jugular.

O líquido ruminal foi homogeneizado e a leitura do $\mathrm{pH}$ feita com potenciômetro digital portátil. Dois $\mathrm{ml}$ de fluido ruminal foram colocados em tubos de ensaios contendo $1 \mathrm{ml}$ de ácido sulfúrico $1 \mathrm{~N}$ e armazena-

Tabela 1 - Composição em base seca do suplemento para a época das secas e das águas

Table 1 - Supplement composition of the dry and wet seasons

\begin{tabular}{|c|c|c|}
\hline $\begin{array}{l}\text { Ingrediente }(\%) \\
\text { Ingredient }\end{array}$ & $\begin{array}{c}\text { Seca } \\
\text { Dry season }\end{array}$ & $\begin{array}{c}\text { Águas } \\
\text { Wet season }\end{array}$ \\
\hline Farelo de soja & 63,0 & 64,25 \\
\hline $\begin{array}{l}\text { Soy bean meal } \\
\text { Farelo de trigo }\end{array}$ & 11,84 & 10,0 \\
\hline Wheat meal & & \\
\hline $\begin{array}{l}\text { Farinha de peixe } \\
\text { Fish meal }\end{array}$ & - & 12,0 \\
\hline $\begin{array}{l}\text { Uréia } \\
\text { Urea }\end{array}$ & 5,0 & 1,0 \\
\hline Refinasilâ & 8,5 & - \\
\hline $\begin{array}{l}\text { Corn gluten feed } \\
\text { Caulim }\end{array}$ & 13 & 13 \\
\hline Calcário & 2,0 & 2,0 \\
\hline Limestone & & \\
\hline $\begin{array}{l}\text { Fosfato bicalcico } \\
\text { Bicalcium fosfate }\end{array}$ & 1,0 & 1,0 \\
\hline $\begin{array}{l}\text { Micro-nutrientes } \\
\text { Micronutrients }\end{array}$ & 0,4 & 0,4 \\
\hline $\begin{array}{l}\text { Rumensin } \AA \\
\text { Rumensin }{ }^{\circledR}\end{array}$ & 0,16 & 0,16 \\
\hline Sal & 6,8 & 6,8 \\
\hline $\begin{array}{l}\text { Salt } \\
\text { Consumo/d (g) }\end{array}$ & 493,0 & 766,0 \\
\hline $\begin{array}{l}\text { Feed intake/daily (g) } \\
\text { IPNDR/d }(\mathrm{g})^{1} \\
\text { RUDPI/d }(g)^{1}\end{array}$ & 64,0 & 124,1 \\
\hline
\end{tabular}

${ }^{1}$ Ingestão de proteína não degradável no rúmen.

${ }^{1}$ Rumen undegradable protein intake.

R. Bras. Zootec., v.32, n.4, p.1002-1012, 2003
Tabela 2 - Composição química do suplemento alimentar para o período das secas e das águas na base seca(\%MS)

Table 2 - Chemical composition of the supplement during the dry and wet season (\%DM)

\begin{tabular}{|c|c|c|}
\hline $\begin{array}{l}\text { Composição } \\
\text { Quimica }\end{array}$ & $\begin{array}{c}\text { Seca } \\
\text { Dry season }\end{array}$ & $\begin{array}{c}\text { Águas } \\
\text { Wet season }\end{array}$ \\
\hline $\begin{array}{l}\text { MS } \\
D M\end{array}$ & 90,7 & 91,3 \\
\hline $\begin{array}{l}\mathrm{NDT}^{*} \\
T D N^{*}\end{array}$ & 76,78 & 73,96 \\
\hline & 46,9 & 43,9 \\
\hline $\begin{array}{l}\text { PNDR * } \\
\text { RUDP * }\end{array}$ & 13,1 & 16,2 \\
\hline $\begin{array}{l}\text { FDN } \\
N D F\end{array}$ & 12,7 & 15,6 \\
\hline $\begin{array}{l}\text { FDA } \\
A D F\end{array}$ & 8,7 & 11,0 \\
\hline $\mathrm{MM}$ & 20,3 & 17,7 \\
\hline $\begin{array}{l}M M \\
\mathrm{Ca} \\
\mathrm{Ca}\end{array}$ & 3,2 & 1,7 \\
\hline $\begin{array}{l}\mathrm{P} \\
P\end{array}$ & 1,2 & 0,6 \\
\hline
\end{tabular}

dos sob refrigeração para análises de nitrogênio amoniacal por colorimetria (Foldager, 1977). Cerca de $50 \mathrm{~mL}$ de líquido ruminal foi centrifugado a $3500 \mathrm{rpm}$ por 15 minutos e em $1 \mathrm{~mL}$ do sobrenadante foram adicionados $0,2 \mathrm{~mL}$ de ácido fórmico P.A., armazenado-se a $-20^{\circ} \mathrm{C}$ até a determinação de ácidos graxos voláteis por cromatografia gasosa (Erwin et al., 1961).

Após retração do coágulo sangüíneo, o soro foi congelado para posterior determinação dos níveis séricos de uréia pelo método enzimático (Kit comercial da marca LABORLAB ${ }^{\circledR}$ ) e para cálculo do nitrogênio na forma de uréia (N-uréia, Bergmeyer, 1985).

O delineamento foi em blocos ao acaso com quatro repetições por tratamento, adicionado do fator de medida de tempo. Os resultados foram analisados através do programa computacional Statistical Analysis System (SAS, 1985) pelo procedimento GLM (PROC GLM), com nível de significância de $5 \%$ para todos os testes realizados. As análises foram realizadas utilizando-se o comando REPEATED gerado pelo procedimento GLM (PROC GLM do SAS). As médias foram comparadas por intermédio do teste Tukey. Na presença de interação entre efeito do tratamento e de tempo, a separação foi feita dentro de cada período de coleta. 


\section{Resultados e Discussão}

As avaliações das pastagens de Brachiaria brizantha e dos bancos de Leucaena leucocephala, por ocasião da colheita do líquido ruminal, encontram-se na Tabela 3.

Em fevereiro, os teores de PB e a digestibilidade in vitro da brachiaria estiveram baixos para a época, provavelmente pelo fato da pastagem estar velha, devido à maior taxa de crescimento da planta e ao longo período de descanso para a gramínea no período (42 dias), propiciando aumento dos constituintes da parede celular (FDN e FDA). Em maio, o maior teor de proteína foi reflexo da adubação de manutenção ocorrida em março de 1999.

Os ganho diário de peso vivo observado estão descritos em Manella et al. (2002). No período seco, nos tratamentos Seca e Ano foram obtidos ganhos individuais médios diários superiores ao Banco e Teste (534 e $486 \times 277$ e $201 \mathrm{~g} / \mathrm{d}$, respectivamente, $\mathrm{P}<0,05$ ) e no período das águas, os ganhos dos tratamentos Ano e Banco foram maiores que os animais Seca e Teste (782 e $741 \times 584$ e $645 \mathrm{~g} / \mathrm{d}$; $\mathrm{P}<0,05)$.

$\mathrm{Na}$ Tabela 4, encontram-se os valores de $\mathrm{pH}$ do líquido ruminal determinados nos bovinos em pastejo nos tratamentos durante as quatro épocas do ano. Verificou-se efeito significativo $(\mathrm{P}=0,0001)$ apenas para época do ano. Nos meses de agosto e maio, as médias de $\mathrm{pH}$ foram maiores $(\mathrm{P}<0,05)$ do que nos meses de Novembro e Fevereiro (7,3 e 7,3 vs 7,1 e 7,0 , respectivamente).

$\mathrm{O}$ valor médio de $\mathrm{pH}$ no presente trabalho foi de 7,1 , concordando com relatos de que dietas com predominância de forragens devem apresentar $\mathrm{pH}$ próximo a neutralidade $(7,0)$ (Kaufman, 1976).

Todavia, deve-se considerar que o método de coleta do líquido ruminal não é o mais indicado para a avaliação desta variável devido a contaminação por saliva. Lavezzo (1986), em coletas realizadas por sonda oro-esofágica, obteve valores médios de $\mathrm{pH}$ do líquido ruminal de 7,3, que também teriam sido superestimados, devido à saliva. Assim, as interpretações dos valores de $\mathrm{pH}$ foram prejudicadas em razão da técnica de coleta de líquido ruminal utilizada.

$\mathrm{O}$ valor médio de $\mathrm{pH}$ no presente trabalho foi de 7,1 , concordando com relatos de que dietas com predominância de forragens devem apresentar $\mathrm{pH}$ próximo a neutralidade (7,0) (Kaufman,1976).

Na Tabela 5, é possível observar as concentrações totais de AGV's, bem como as proporções molares do ácido acético, do propiônico e do butírico, devido aos tratamentos durante as diferentes épocas do ano.

Entre as proporções molares de ácido acético nos tratamentos estudados e as quatro épocas do ano houve interação. Em fevereiro, o tratamento Ano teve menor proporção $(\mathrm{P}<0,05)$ de acetato, quando comparado com os animais da Seca e Banco $(81,8 v s$ $83,8$ e $83,9 \% \mathrm{mM})$. Foi verificado que, na coleta

Tabela 3 - Disponibilidade (kgMs/ha), e composição químico bromatologica (\%MS) da pastagem nos meses do ano (agosto, novembro, fevereiro e maio) em que foram realizadas as coletas de líquido ruminal

Table 3 - Availabillity ( $\mathrm{kg} / \mathrm{DM} / \mathrm{ha}$ ) and chemical composition (\%DM) of Brachiaria brizantha e da Leucaena leucocephla at the moment that the rumen fluid was collected

\begin{tabular}{|c|c|c|c|c|c|c|c|c|}
\hline \multirow{2}{*}{$\begin{array}{l}\text { Análise química } \\
\text { Chemical composition }\end{array}$} & \multicolumn{4}{|c|}{ Brachiaria brizantha } & \multicolumn{4}{|c|}{ Leucaena leucocephala } \\
\hline & $\begin{array}{l}\text { Ago. } \\
\text { Aug. }\end{array}$ & $\begin{array}{l}\text { Nov. } \\
\text { Nov }\end{array}$ & $\begin{array}{l}\text { Fev. } \\
\text { Feb. }\end{array}$ & $\begin{array}{l}\text { Maio } \\
\text { May }\end{array}$ & $\begin{array}{l}\text { Ago. } \\
\text { Aug. }\end{array}$ & $\begin{array}{l}\text { Nov. } \\
\text { Nov }\end{array}$ & $\begin{array}{l}\text { Fev. } \\
\text { Feb. }\end{array}$ & $\begin{array}{l}\text { Maio } \\
\text { May }\end{array}$ \\
\hline $\begin{array}{l}\text { MS } \\
D M\end{array}$ & 51,8 & 26,4 & 24,5 & 26,7 & 31,8 & 26,6 & 23,9 & 26,3 \\
\hline $\begin{array}{l}\text { Disponibilidade } \\
\text { Availability }\end{array}$ & 4793 & 3439 & 4232 & 3954 & 1857 & 3588 & 3423 & 1987 \\
\hline $\begin{array}{l}\text { Matéria verde }(\%) \\
\text { Green forage }(\%)\end{array}$ & 56,9 & 83,8 & 81,7 & 89,5 & - & - & - & - \\
\hline $\begin{array}{l}\mathrm{PB} \\
\mathrm{CP}\end{array}$ & 3,5 & 9,6 & 5,5 & 9,6 & 25,4 & 26,7 & 25,3 & 27,6 \\
\hline $\begin{array}{l}\text { FDN } \\
N D F\end{array}$ & 75,6 & 71,8 & 78,0 & 71,2 & 40,3 & 34,9 & 51,5 & 32,5 \\
\hline $\begin{array}{l}\text { FDA } \\
A D F\end{array}$ & 43,7 & 38,0 & 46,8 & 37,1 & 31,5 & 22,6 & 38,3 & 24,1 \\
\hline $\begin{array}{l}\text { Digestibilidade in vitro } \\
\text { In vitro digestibility }\end{array}$ & 46,1 & 64,9 & 35,7 & 50,3 & 61,2 & 63,8 & 47,8 & 63,7 \\
\hline
\end{tabular}

R. Bras. Zootec., v.32, n.4, p.1002-1012, 2003 
Tabela 4 - Valor de $\mathrm{pH}$ do líquido ruminal de bovinos nas diferentes épocas do ano

Table 4 - Ruminal $\mathrm{pH}$ of beef cattle at different year seasons

\begin{tabular}{|c|c|c|c|c|c|c|c|}
\hline \multirow{2}{*}{$\begin{array}{l}\text { Época do ano } \\
\text { Year season }\end{array}$} & \multicolumn{4}{|c|}{$\begin{array}{c}\text { Tratamento } \\
\text { PH }\end{array}$} & \multirow[b]{2}{*}{ Média } & \multirow[b]{2}{*}{ C.V. } & \multirow[b]{2}{*}{ P. } \\
\hline & Ano & Secas & Banco & Teste & & & \\
\hline Agosto & 7,3 & 7,3 & 7,2 & 7,1 & $7,3^{\mathrm{a}}$ & 3,4 & -1 \\
\hline $\begin{array}{l}\text { August } \\
\text { Novembro } \\
\text { November }\end{array}$ & 7,1 & 7,0 & 7,0 & 7,1 & $7,1^{\mathrm{b}}$ & 2,2 & - \\
\hline $\begin{array}{l}\text { Fevereiro } \\
\text { February }\end{array}$ & 6,9 & 7,0 & 7,1 & 6,9 & $7,0^{\mathrm{b}}$ & 3,6 & - \\
\hline $\begin{array}{l}\text { Maio } \\
\text { May }\end{array}$ & 7,1 & 7,4 & 7,3 & 7,2 & $7,3^{\mathrm{a}}$ & 2,4 & - \\
\hline Média & 7,1 & 7,1 & 7,2 & 7,1 & 7,1 & 2,9 & 0,2227 \\
\hline
\end{tabular}

a, ${ }^{b}$ Médias com letras diferentes sobrescritas na mesma coluna são significativamente diferentes $(P<0,05)$ (Means with different letters in the same row are significantly different at $P<.05$ ).

Efeito da época do ano: $P=0,0001$ (year season effect: $P=.001$ ).

realizada em maio, os tratamentos Seca, Banco e Teste apresentaram proporções maiores $(\mathrm{P}<0,05)$ do que no tratamento $\operatorname{Ano}(84,6,83,2,85,2$ vs $80,7 \% \mathrm{mM})$.

Nos AGV's, apenas nas coletas realizadas em maio observaram-se diferenças $(\mathrm{P}<0,05)$ entre os tratamentos, sendo que o Ano apresentou 77,2 mM, maior do que o do tratamento testemunha, com 55,9 mM. O aumento das concentrações de AGV's, devido ao fornecimento de concentrado protéico, está relacionado com aumento na concentração de $\mathrm{N}-\mathrm{NH}_{3}$ ruminal (Driedger \& Loerch, 1999) e na ingestão de matéria seca (Poppi \& Mclennan, 1995; Olson et al., 1999), resultando em maior fornecimento de substrato para fermentação microbiana (Petit \& Flipot, 1992). De modo geral, a ausência de efeito na concentração total de AGV's entre os tratamentos, exceto em maio, pode ter ocorrido em função da diluição pela maior salivação dos animais no ato da coleta.

Animais recebendo concentrado apresentaram menor proporção de ácido acético que animais alimentados exclusivamente com volumoso (Delcurto et al., 1990a; Albro et al., 1993; Fike et al., 1995; Koster et al., 1996). Nas dietas com alta proporção de volumoso, como nos tratamentos Banco e Teste, a fermentação ocorre preferencialmente pela via do acetato, segundo Church et al. (1988). Como a leucena contém baixa concentração de carboidratos solúveis, isto favorece a produção de acetato (Bonsi et al., 1995).

As proporções molares de ácido propiônico apresentaram interação significativa entre época do ano e tratamentos. No mês de agosto, os animais dos tratamentos Ano e seca, por estarem recebendo a mesma dieta, apresentaram aumento $(\mathrm{P}<0,05)$ na proporção de propionato em relação ao Banco e Teste $(14,8$ e 13,8 vs. $10,9$ e $10,9 \% \mathrm{mM})$. Na coleta de fevereiro, observou-se maior proporção de ácido propiônico $(\mathrm{P}<0,05)$ no tratamento Ano $(14,6 \% \mathrm{mM})$. Em maio, foram verificadas tendências semelhantes às de fevereiro, em que a proporção de propionato do tratamento Ano $(14,9 \% \mathrm{mM})$ foi maior $(\mathrm{P}<0,05)$ que os outros tratamentos.

Em todas as épocas do ano, os animais que receberam o suplemento protéico apresentaram maiores proporções deácido propiônico, assim como nos estudos de McCoullun \& Galyean (1985), Delcurto et al. (1990a) e Delcurto et al. (1990b). Freeman et al. (1992), ao fornecerem diferentes níveis de proteína para novilhos de corte em pastejo, verificaram aumento apenas na proporção molar de ácido propiônico, sem alterações nos AGV's totais. Entretanto, alguns autores relataram que não obeservaram alterações nas proporções molares de ácido propiônico, quando forneceram concentrado protéico para bovinos a pasto (Petit \& Flipot, 1992; Shain et al., 1998; Driedger et al., 1999).

As proporções de ácido butírico do líquido ruminal dos bovinos em pastejo foram maiores $(\mathrm{P}<0,05)$ no tratamento Banco em relação ao tratamento Ano $(5,1$ $x$ 4,1). A suplementação protéica não aumentou a proporção de ácido butírico, assim como nas observações feitas por Delcurto et al. (1990b), Freeman et al. (1992) e Driedger \& Loerch (1999). Estas observações são contrárias aos relatos de Caton et al. (1988), Delcurto et al. (1990a) e Shain et al. (1998). Os animais que tiveram acesso ao banco de proteína de Leucaena leucocephala apresentaram aumento na produção de ácido butírico. Bonsi et al. (1995) 
Tabela 5 - Ácidos graxos voláteis (AGV's) do líquido ruminal de bovinos em diferentes épocas do ano Table 5 - Volatile fatty acids (FVA's) of rumen fluid of beef cattle grazing at diferent year seasons

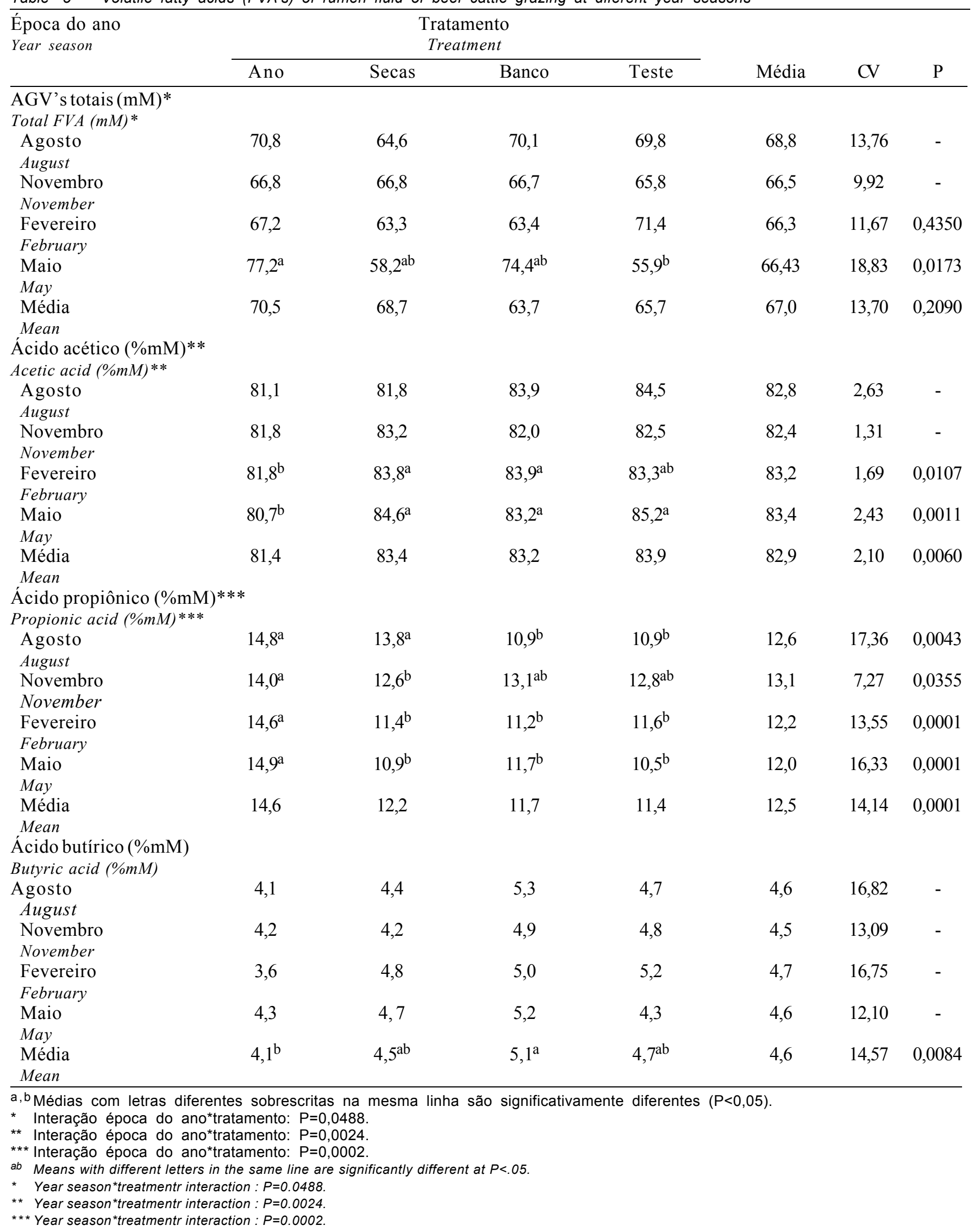


encontraram efeitos semelhantes com animais alimentados com leucena.

Nas proporções molares de ácido acético:propiônico, houve interação entre época do ano e tratamento. As menores relações observadas ocorreram em função do aumento na proporção de ácido propiônico observada nos tratamentos em que os animais receberam a suplementação.

$\mathrm{O}$ fornecimento de proteína alterou as proporções dos ácidos e diminui a relação acetato:propionato, devido ao aumento de ácido propiônico, em associação à diminuição de acético. Animais alimentados principalmente com volumosos tendem a apresentar populações bacterianas predominantemente, produtoras de acetado, mas com concentrados na dieta, destacamse as produtoras de propionato (Church, 1988).

A maior produção de ácido propiônico, em vez de ácido acético ou butírico nos animais suplementados ocasionou uma maior eficiência energética, quer seja pelo maior aporte de substâncias gluconeogénicas (ácido propiónico), ou pela "retenção" de energia devido a diminuição nas perdas via metano $\left(\mathrm{CH}_{4}\right)$, favorecendo, em parte, o melhor desempenho para animais suplementados. Whitelaw et al. (1984) observaram relação inversa entre as produções de metano e a concentração molar de ácido propiónico.

Os animais nos tratamentos com acesso ao banco de leucena apresentaram efeitos apenas no ácido butírico, enquanto os AGV's totais, o acético e o propiônico não foram alterados. Por outro lado, Bonsi et al. (1995) não só observaram maiores produções de AGV's como alterações nas proporções individuais dos ácidos.

Os valores médios dos compostos nitrogenados amoniacais $\left(\mathrm{N}-\mathrm{NH}_{3}\right)$ no líquido ruminal encontram-se na Tabela 6. No mês de agosto, os tratamentos Ano e Seca resultaram em valores semelhantes de $\mathrm{N}_{-} \mathrm{NH}_{3}$, 7,5 e 7,3 mg/dL, respectivamente. Esta ocorrência é explicada pelo fato de que em ambos os tratamentos os animais receberam o concentrado protéico. Os valores de $\mathrm{N}-\mathrm{NH}_{3}$ destes tratamentos foram maiores $(\mathrm{P}<0,05)$ que os dos animais do Banco $(1,3 \mathrm{mg} / \mathrm{dL})$ e Teste $(2,0 \mathrm{mg} / \mathrm{dL})$. Em fevereiro $(\mathrm{P}=0,0026)$, o valor de $\mathrm{N}-\mathrm{NH}_{3}$ para os animais do grupo Ano $(8,5 \mathrm{mg} / \mathrm{dL})$ foi maior $(\mathrm{P}<0,05)$ que os dos demais tratamentos. Efeitos semelhantes ocorreram em maio, com valor maior $(\mathrm{P}<0,05)$ no tratamento Ano $(7,8 \mathrm{mg} / \mathrm{dL})$.

A maior concentração de $\mathrm{N}-\mathrm{NH}_{3}$ nos tratamentos suplementados foi semelhante aos encontrados por Del Curto et al. (1990a), Fike et al. (1995), Hennessy et al. (1995), Franco et al. (1996), Valadares et al. (1997), Franco (1997), Shain et al.(1998) e Zeoula et al. (1999).

Os valores de $\mathrm{N}-\mathrm{NH}_{3}$ obtidos no presente trabalho foram menores que os descritos por Franco (1997) (7,1 a 16,9 mg/dL) e Franco et al. (1996) (17 a $27,9 \mathrm{mg} / \mathrm{dL}$ ), que suplementaram bovinos em pastejo com fontes protéicas de diferentes degradabilidades, no período das águas e secas, respectivamente.

Em trabalhos realizados por Caton et al. (1988) e Shain et al. (1998) foram relatadas variações de N$\mathrm{NH}_{3}$ semelhantes às do presente trabalho. No primeiro a variação foi de 3,6 a $7,1 \mathrm{mg} / \mathrm{dl}$ para animais recebendo suplemento a pasto $(45 \% \mathrm{~PB}$, na $\mathrm{MO})$, e para o Teste de 1,3 a 2,2 mg/dl. Shain et al. (1998) forneceram níveis crescentes de uréia e observaram valores de $\mathrm{N}_{-} \mathrm{NH}_{3}$ entre 1,7 e 7,9 mg/dl. Em ambos os trabalhos, os autores associaram a maior degradabilidade da proteína com elevados valores de $\mathrm{N}^{-\mathrm{NH}_{3}}$.

Os valores médios para os animais suplementados no mês de agosto nos tratamentos Ano $(7,5 \mathrm{mg} / \mathrm{dL})$ e Seca $(7,3 \mathrm{mg} / \mathrm{dL})$ e nos meses de fevereiro $(8,5 \mathrm{mg} / \mathrm{dL})$ e maio $(7,8 \mathrm{mg} / \mathrm{dL})$, para o tratamento Ano, foram maiores que os limites propostos por Slyter et al. (1979) de 2,0 a $5,0 \mathrm{mg} / \mathrm{dL}$, indicando que as concentrações de $\mathrm{N}-\mathrm{NH}_{3}$ não foram limitantes para a fermentação ruminal.

Os tratamentos Teste, Banco, e Seca (novembro fevereiro e maio) apresentaram valores próximos ao limite mínimo proposto por Slyter et al. (1979) e semelhantes aos encontrados por Caton et al. (1988) para animais submetidos somente ao pasto exclusivo $(1,3$ a $2,2 \mathrm{mg} / \mathrm{dL})$. Alguns autores relataram que

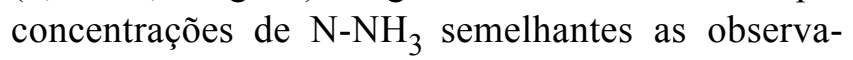
das não foram limitantes para a síntese de proteína microbiana (Mullik etal., 1998), ou para a digestibilidade da forragem (Kang-Mesnarich \& Broderik, 1981; Milton \& Brandt, 1994).

A concentração de $\mathrm{N}-\mathrm{NH}_{3}$ observada em novembro para o tratamento Ano foi relativamente menor $(3,5 \mathrm{mg} / \mathrm{dL})$, quando comparada às três outras avaliações, apesar dos elevados teores de proteína da forragem. Neste período as pastagens apresentaram maior digestibilidade (64\%) e, conseqüentemente, maior disponibilidade de carboidratos, favorecendo a microbiota ruminal utilizar com maior eficiência o $\mathrm{N}-\mathrm{NH}_{3}$ para a síntese de proteína (Firkins, 1996).

Nos animais com acesso ao Banco, os valores de $\mathrm{N}-\mathrm{NH}_{3}$ foram consideravelmente menores (1,3 a 3,1 $\mathrm{mg} / \mathrm{dL}$ ) que os descritos por Abdulrazak et al. (1997) na suplementação ( 15 ou $30 \mathrm{~g} \mathrm{MS} / \mathrm{kg}^{0,75}$ ) de Gliricidia sepium $(8,0$ a $10,0 \mathrm{mg} / \mathrm{dL})$ ou Leucaena 
Tabela 6 - Valores médios da concentração de compostos nitrogenados amoniacais $\left(\mathrm{N}-\mathrm{NH}_{3}\right)$ do líquido ruminal de bovinos nas diferentes épocas do ano

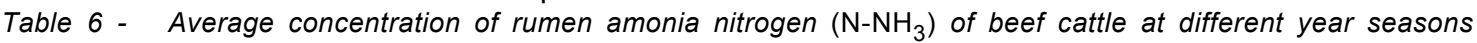

\begin{tabular}{|c|c|c|c|c|c|c|c|}
\hline \multirow{2}{*}{ 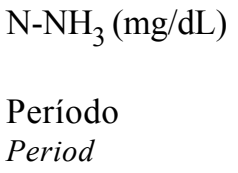 } & \multicolumn{4}{|c|}{$\begin{array}{c}\text { Tratamento } \\
\text { Treatment }\end{array}$} & \multirow[b]{2}{*}{ Média } & \multirow[b]{2}{*}{$\mathrm{CV}$} & \multirow[b]{2}{*}{$\mathrm{P}$} \\
\hline & Ano & Secas & Banco & Teste & & & \\
\hline $\begin{array}{l}\text { Agosto } \\
\text { August }\end{array}$ & $7,5^{\mathrm{a}}$ & $7,3^{\mathrm{a}}$ & $1,3^{b}$ & $2,0^{\mathrm{b}}$ & 4,4 & 72,64 & 0,0013 \\
\hline $\begin{array}{l}\text { Novembro } \\
\text { November }\end{array}$ & 3,5 & 2,0 & 2,4 & 1,7 & 2,4 & 46,79 & - \\
\hline $\begin{array}{l}\text { Fevereiro } \\
\text { February }\end{array}$ & $8,5^{\mathrm{a}}$ & $1,3^{b}$ & $1,4^{b}$ & $1,7^{\mathrm{b}}$ & 3,2 & 113,00 & 0,0026 \\
\hline $\begin{array}{l}\text { Maio } \\
\text { May }\end{array}$ & $7,8^{\mathrm{a}}$ & $2,6^{\mathrm{b}}$ & $3,1^{b}$ & $2,2^{b}$ & 3,9 & 66,36 & 0,0001 \\
\hline $\begin{array}{l}\text { Média } \\
\text { Mean }\end{array}$ & 6,8 & 3,0 & 2,1 & 1,9 & 3,4 & 81,64 & 0,0014 \\
\hline
\end{tabular}

a,b Médias com letras diferentes sobrescritas na mesma linha são significativamente diferentes $(P<0,05)$.

Efeito da época do ano: $P=0,0001$.

ab Means with different letters in the same line are significantly different at $P<.05$.

Year season effect: $P=0.001$.

leucocephala $(9,5 \mathrm{a} 11,1 \mathrm{mg} / \mathrm{dL})$. Os baixos valores de $\mathrm{N}-\mathrm{NH}_{3}$ no presente trabalho podem ser explicados, provavelmente, pelo menor consumo da leucaena na forma de banco de proteína em relação ao trabalho citado anteriormente, apesar de os animais terem livre acesso. Bonsi et al. (1995) também relataram baixos valores de $\mathrm{N}_{-} \mathrm{NH}_{3}$ em animais recebendo leucaena, o que se deve à lenta degradabilidade da proteína da leguminosa.

Outros trabalhos demonstraram que a baixa degradabilidade da proteína da leucena em parte se deve à alta taxa de passagem da folha, devido ao pequeno tamanho de partícula (Franzolin Neto et al., 1992; All \& Stobbs, 1994; Bonsi et al., 1995). Outro fator responsável para redução da degradação da proteína pode ser pelo tanino ligado a mesma (Reid et al., 1974). Entretanto, isto não foi prejudicial, pois a leguminosa proporcionou maior aporte de proteína não degradável no rúmen chegando aos intestinos, favorecendo elevados ganhos de peso para os animais no período das águas (Manella et al., 2002).

$\mathrm{O}$ tratamento Teste apresentou baixos valores de $\mathrm{N}-\mathrm{NH}_{3}(1,7$ a $2,2 \mathrm{mg} / \mathrm{dL})$, mesmo quando a forragem apresentou teores de proteína mais elevados, que, segundo Minson (1990) e Prior et al. (1998), são consistentes para gramíneas tropicais. Hafley et al. (1989) observaram poucos valores acima de $5 \mathrm{mg} / \mathrm{dL}$ de $\mathrm{N}-\mathrm{NH}_{3}$ para animais em pastagem de verão com $\mathrm{PB}$ entre 8 e $14 \%$. As concentrações de $\mathrm{N}-\mathrm{NH}_{3}$ para animais recebendo exclusivamente volumosos esti- veram abaixo do ideal de $5 \mathrm{mg} / \mathrm{dL}$.

Malafaia etal(1997) observaram que 34,12 e 27,73\% da PB da Brachiaria brizantha encontra-se na forma das frações $\mathrm{B}_{3}$ e $\mathrm{C}$, respectivamente, ou seja, mais que $50,0 \%$ da proteína desta gramínea é pouco degradável no rúmen $\left(\mathrm{B}_{3}\right)$ ou indisponível $(\mathrm{C})$ para a ação microbiana no ambiente ruminal (Siniffen et al., 1992).

$\mathrm{O}$ não aumento das concentrações de $\mathrm{N}-\mathrm{NH}_{3}$ durante os períodos de melhor qualidade das pastagens ( $\mathrm{PB}>7,0 \%$ ) para os tratamentos Seca e Teste, pode ter ocorrido em função das observações feitas por Malafaia et al.(1997). Estas informações associadas aos achados do presente trabalho, indicam que mesmo no período das águas, a quantidade de PDR na $B$. brizantha pode ser insuficiente para manter os níveis adequados de $\mathrm{N}^{-\mathrm{NH}_{3}}$.

As concentrações séricas de N-uréia apresentadas na Tabela 7 mostraram efeitos semelhantes as das concentrações de $\mathrm{N}-\mathrm{NH}_{3}$ no rúmen.

Em agosto, os tratamentos Ano e Secas apresentaram maiores valores de $\mathrm{N}$-uréia $(\mathrm{P}<0,05)$ que os tratamentos Banco e Teste (12,6 e 12,6 vs 4,3 e 2,1 $\mathrm{mg} / \mathrm{dL})$. No mês de novembro, apenas os tratamentos Ano $(5,6 \mathrm{mg} / \mathrm{dL})$ e Teste $(3,4 \mathrm{mg} / \mathrm{dL})$ apresentaram diferenças $(\mathrm{P}<0,05)$. Os animais do tratamento Ano, em fevereiro apresentaram as maiores concentrações séricas de $\mathrm{N}$-uréia $(\mathrm{P}<0,05)$. Na observação de maio, houve tendência semelhante ao período anterior, no qual o tratamento Ano $(10,7 \mathrm{mg} / \mathrm{dL})$ resultou em maiores valores $(\mathrm{P}<0,05)$. 
Em agosto, os tratamentos Ano e Secas apresentaram maiores valores de $\mathrm{N}$-uréia $(\mathrm{P}<0,05)$ que os tratamentos Banco e Teste $(12,6$ e 12,6 vs 4,3 e $2,1 \mathrm{mg} / \mathrm{dL}$ ). No mês de novembro, apenas os tratamentos Ano $(5,6 \mathrm{mg} / \mathrm{dL})$ e Teste $(3,4 \mathrm{mg} / \mathrm{dL})$ apresentaram diferenças $(\mathrm{P}<0,05)$. Os animais do tratamento Ano, em fevereiro, apresentam as maiores concentrações séricas de $\mathrm{N}$-uréia $(\mathrm{P}<0,05)$. Na observação de maio, houve tendência semelhante ao período anterior, em que foram obtidos os maiores valores $(\mathrm{P}<0,05)$ para o tratamento Ano $(10,7 \mathrm{mg} / \mathrm{dL})$.

Apenas uma fração do nitrogênio suplementado a dieta é retido como ganho de peso adicional, e o restante é metabolizado em uréia, aumentando as concentrações séricas deste último composto (Kunkle \& Hopkins, 1999). Dessa forma, o N-uréia sangüíneo é utilizado como indicativo do balanço protéico, sendo que os limites de uréia sangüínea indicativos da adequada ingestão protéica são de 9,0 a $12 \mathrm{mg} / \mathrm{dL}$ (Hammond et al., 1993). Altas concentrações de uréia sérica $(>12 \mathrm{mg} / \mathrm{dL})$ podem comprometer o desempenho animal, devido à maior demanda energética para excreção na mesma (Hammond, 1994).

As concentrações sangüíneas de $\mathrm{N}$-uréia observadas no presente trabalho estão de acordo com as relatadas na literatura (Moss \& Murray, 1992; Pitts et al., 1992; Simpson et al., 1999; Kunkle \& Hopkins, 1999), em que a suplementação protéica elevou os valores de uréia sérica. $\mathrm{O} \mathrm{N}$-uréia teve o mesmo comportamento que as concentrações de $\mathrm{N}_{-} \mathrm{NH}_{3}$, mostrando estreita relação entre estas variáveis, que também foi relatada por Moss \& Murray (1992), Russel (1992) e Valadares et al. (1997).

Pitts et al. (1992) suplementaram bovinos de corte no verão e na primavera com três níveis de farelo de algodão, por três anos consecutivos. Os níveis mais elevados do suplemento mantiveram valores de Nuréia sangüínea mais altos (19 a $29 \mathrm{mg} / \mathrm{dL}$ ). As concentrações de $\mathrm{N}$-uréia no presente trabalho nos animais suplementados foram menores, porém com comportamento semelhante ao descrito por aqueles autores.

No presente trabalho, os animais suplementados nos meses de agosto (Ano e Seca), fevereiro e maio (Ano) apresentaram teores de uréia sérica variando de 10,7 a 12,6 mg/dL, indicando valores adequados de ingestão protéica (Hamond et al., 1993). Apenas em novembro, os animais suplementados (Ano, 5,6 mg/dL) mostraram valores menores que os sugeridos por aqueles autores. Os animais com acesso ao banco de proteína apresentaram valores em todas as épocas abaixo do considerado ótimo.

As concentrações de $\mathrm{N}$-uréia nos animais suplementados no cocho indicam bom aproveitamento de proteína e energia, esta obtida da forragem. Dietas protéicas com baixa disponibilidade de energia resultam em altas concentrações séricas de $\mathrm{N}$-uréia, porém, ao aumentar a energia na dieta, há diminuição nas concentrações sangüíneas (Pitts et al., 1992). Esta última afirmação pode explicar o ocorrido em novembro, devido à maior digestibilidade da pastagem.

Tabela 7 - Uréia sérica ( $\mathrm{N}$-uréia) de bovinos nas diferentes épocas do ano.

Table 7 - Blood urea nitrogen (N-urea) of beef cattle grazing at different year seasons

\begin{tabular}{|c|c|c|c|c|c|c|c|}
\hline \multirow[b]{2}{*}{$\begin{array}{l}\text { Período } \\
\text { Period }\end{array}$} & \multicolumn{4}{|c|}{$\begin{array}{c}\text { Tratamento } \\
\text { Treatment } \\
\text { N-uréia }(\mathrm{mg} / \mathrm{dL})\end{array}$} & \multirow[b]{2}{*}{ Média } & \multirow[b]{2}{*}{$\mathrm{CV}$} & \multirow[b]{2}{*}{$\mathrm{P}$} \\
\hline & Ano & Secas & Banco & Teste & & & \\
\hline $\begin{array}{l}\text { Agosto } \\
\text { August }\end{array}$ & $12,6^{a}$ & $12,6^{\mathrm{a}}$ & $4,3^{b}$ & $2,1^{b}$ & 7,9 & 69,24 & 0,0001 \\
\hline $\begin{array}{l}\text { Novembro } \\
\text { November }\end{array}$ & $5,6^{\mathrm{a}}$ & $3,6^{\mathrm{ab}}$ & $4,6^{\mathrm{ab}}$ & $3,4^{b}$ & 4,3 & 29,99 & 0,0300 \\
\hline $\begin{array}{l}\text { Fevereiro } \\
\text { February }\end{array}$ & $11,3^{\mathrm{a}}$ & $3,3^{b}$ & $3,2^{\mathrm{b}}$ & $2,7^{\mathrm{b}}$ & 5,1 & 75,92 & 0,0001 \\
\hline $\begin{array}{l}\text { Maio } \\
\text { May }\end{array}$ & $10,7^{\mathrm{a}}$ & $5,1^{\mathrm{b}}$ & $5,6^{\mathrm{b}}$ & $4,0^{\mathrm{b}}$ & 6,4 & 44,78 & 0,0001 \\
\hline $\begin{array}{l}\text { Média } \\
\text { Mean }\end{array}$ & 10,1 & 6,0 & 4,4 & 3,1 & 5,9 & 65,16 & 0,0001 \\
\hline
\end{tabular}

a,b Médias com letras diferentes sobrescritas na mesma linha são significativamente diferentes $(P<0,05)$.

Efeito da época do ano: $P=0,0001$.

ab Means with different letters in the same line are significantly different at $P<.05$.

Year season effect: $P=0.001$.

R. Bras. Zootec., v.32, n.4, p.1002-1012, 2003 


\section{Conclusões}

A suplementação alterou os parâmetros de fermentação ruminal, favorecendo a maior atividade microbiana, devido ao maior aporte de $\mathrm{N}-\mathrm{NH}_{3}$ ruminal, e o aumento nas proporções de ácido propiônico possibilitou maior retenção de energia, sendo que tais alterações são em parte responsáveis pelo melhor desempenho animal. O banco de leucena não provocou alterações no rúmen, porém a alta taxa de passagem da proteína para o duodeno permitiu desempenho animal, no período das águas, semelhante aos animais suplementados.

Os resultados sugerem que, para pastagens de B. brizantha no período das águas, é necessária a suplementação com fontes de proteína para otimização do ambiente ruminal. Entretanto, mais trabalhos avaliando aspectos da fermentação ruminal de animais pastejando gramíneas tropicais, suplementados ou não, precisam ser realizados, auxiliando na formulação de suplementos estratégicos.

\section{Literatura Citada}

ABDULRAZAK, S.A.; MUINGA, R.W.; THORPE, W. et al. Supplementation with Gliricidia sepium and Leucaena leucocephala on voluntary food intake, digestibility, rumen fermentation and live weight of crossbred steers offered Zea mays stover. Livestock Production Science, v.49, p.53-62, 1997.

ALBRO, J.D.; WEBER, D.W.; DELCURTO, T. Comparison of whole, raw soybeans, extrused soybeans, or soybean meal and barley on digestive characteristcs and performance of weaned beff steers consuming mature grass hay. Journal of Animal Science, v.71, p.26-32, 1993.

AII, T.; STOBBS, T.H. Solubility of the protein of tropical pastures species and rate of its digestion in the rumen. Animal Feed Science and Technology, v.5, p.83-192, 1994.

ASOCIATION OF OFICIAL ANALIYTICAL CHEMISTS AOAC. Oficial methods of analyses. 15.ed. Washington: 1990. v.1, p.72-74.

BALDWIN, R.L. Use of isolated ruminal ephitelial cells in the study of rumen metabolis. Journal of Nutrition, v.128, p.293-296, 1998. (suplement)

BERGMEYER, H.D. Methods of enzymatic analysis. VCH Publishers, 1985. v.9, p.449-453.

BONSI, M.L.K.; OSUJI, P.O.; TUAH, A.K. Effect of supplementing teff straw with different levels of leucaena or sesbania leaves on the degradabilities of teff straw, sesbania, leucaena, tagasaste and vernonia and certain rumen and blood metabolites in Ethiopian Menz sheep. Animal Feed Science and Technology, v.52, p.101-129, 1995.

CATON, J.S.; FREEMAN, A.S.; GALYEAN, M.L. Influence of protein supplementation on forage intake, in situ forage disappearence, ruminal fermentation and digesta passage rates in steers grazing dormant blue grama rangeland. Journal of Animal Science, v.66, p.2262-2271, 1988.

CHURCH, D.C. The ruminant animal: digestive physiology and nutrition. Englewood Cliffs: Waveland Press, 1988. 563p.
DELCURTO, R.C.; COCHRAN, R.C.; HARMON, D.L et al. Supplementation of dormant tallgrass-praire forage: I. Influence of varying supplemental protein and (or) energy levels on forage utilization characteristics of beef steers in confinament. Journal of Animal Science, v.68, p.515-531, 1990a.

DELCURTO, T.; COCHRAN, R.C.; CORAH, L.R. et al.. Supplementation of dormant tallgrass-praire forage: II. Peformance and forage utilization characteristics in grazing beef cattle receiveing supplements of diferents concentrations. Journal of Animal Science, v.68, p.532-542, 1990 b.

DRIEDGER, L.J.; LOERCH, S.C. Effects of protein and source on nutrient digestibility by mature steers limit-fed highconcentrte diets. Journal of Animal Science, v.77, p.960-966, 1999.

ERWIN, E.S.; MARCO, G.J.; EMERY, E.M. Volatile fatty acid analyses of blood and rumen fluid by gas chromatography. Journal of Dairy Science, v.44, n.9, p.1768-1771, 1961.

ELIZALDE, J.C.; CREMIN JR., J.D.; FAULKNER, D.B. et al. Perfomance and digestion by steers grazing tall fescue and suplemented with energy and protein. . Journal of Animal Science, v.76, p.1691-1701, 1998.

FIKE, G.D.; SIMMS, D.D.; COCHARN, R.C. et al. Protein supplementation of amoniated wheat straw: effect on performance and forage utilization of beef cattle. Journal of Animal Science, v.73, p.1595-1601, 1995.

FIRKINS, J.L. Maximizing microbial protein syntesis in the rumen. Journal of Nutrition, v.126 (supplement), p.1347s-1354s, 1996.

FOLDAGER, J. Protein requirement and non proteinEast Lasing: Michigan Estate University nitrogen for high producing cow early in lactation. East Lasing: Michigan Estate University, 1977. Ph.D. (Thesis). Michigan Estate University, 1977.

FRANCO, G.L. Avaliação dos parâmetros ruminais de bovinos suplementados a pasto na estação das águas. Jaboticabal: Universidade Estadual Paulista, 1997. 75p Dissertação (Mestrado em Zootecnia) - Universidade Estadual Paulista, 1997.

FRANCO, A.V.M.; FRANCO, G.L.; ANDRADE, P. Efeito da degradabilidade da proteína e níveis de suplementação sobre os parâmetros ruminais $\mathrm{pH}$ e N-NH 3 . In: REUNIÃO ANUAL DA SOCIEDADE BRASILEIRA DE ZOOTECNIA, 38., 1996, Fortaleza. Anais... Fortaleza, 1996. p.333-334.

FRANZOLIN NETO, R.; ANDRADE, P.; OCAMPOS, D. Degradabilidade da proteína e desdobramento da mimosina da Leucaena leucocephala (Lam) de with no rúmen de bufalos sob dietas com diferentes níveis de proteínas. Brasilian Journal of Veterinary Research and Animal Science, v.29, p.375-377, 1992.

FREEMAN, A.S.; GALYEAN, M.L.; CATON, J.S. Effects of supplement percentage and feeding level on intake, ruminal fermentation, and digesta passage in beef steers fed praire hay. Journal of Animal Science, v.70, p.1562-1572, 1992.

HAFLEY, J.L.; ANDERSON, B.E.; KLOPFENSTEIN, T.J. Rumen protein degradation of warm season grass. Journal of Animal Science, v.67, p.304 (Abstract), 1989. (Supplement 1)

HAMMOND, A.C.; KUNKLE, W.E., BATES, D.B. et al. Use of blood urea nitrogen concentration to predict response to protein or energy supplementation in grazing cattle. In: PROCCEDINGS OF INTERNATIONAL GRASSLAND CONGRESS, 17., 1993, New Zealand. Proceedings... New Zealand: New Zealand Grassland Assosiation, 1993. p.189.

HAMMOND, A.C. High "BUN" level a sign of protein waste. Agricultural Research, 1994.

HENNESSY, D.W.; KOHUN, P.J.; WILLIAMSON, P.J. et al. The effect of nitrogen and protein supplementation on feed

R. Bras. Zootec., v.32, n.4, p.1002-1012, 2003 
intake, growth and digestive function of steer with Bos indicus and Bos taurus genotypes when fed a low quality grass hay. Australian Journal of Agriculture Research, v.46, p.1121-1136, 1995.

KANG-MESNARICH, J.H.; BRODERICK, G.A. Effects of incremental urea supplementation on ruminal ammonia concentration and bacterial protein formation. Journal of Animal Science, v.51, p.422-431, 1981.

KAUFMAN, W. Influence of composition ofthe ration and the feeding frequency on the $\mathrm{pH}$ regulation in the rumen and on feed intake in ruminants. Livestock Production Science, v.3, n.2, p.103-114, 1976.

KOSTER, H.H., COCHRAN, R.C., TITGEMEYER, E.C. et al. Effect of increasing degradable intake protein on intake and digestion of low quality, tallgraass-Praire tall-grass praire forage by beef cows. Journal of Animal Science, v.74, p.2473-2481, 1996.

KUNKLE, W.E.; HOPKINS, D.I. Is methionine the first limiting amino acid for growing cattle fed forages? In: ANNUAL FLORIDA NUTRITION SYMPOSIUM, 10., 1999, Gainsville. Proccedings ... Gainsville: University of Florida, 1999. p.19-29.

LAVEZZO, O.E.N.M. Influência de métodos de coleta de fluido ruminal sobre os parâmetros de fermentação, em bovinos, alimentados com diferentes fontes de proteína. Piracicaba: Escola Superior de Agricultura "Luiz de Queiroz", 1986. 167p. Dissertação (Mestrado em Zootecnia) - Escola Superior de Agricultura "Luiz de Queiroz", 1986.

LOURENÇO, A.J.; MATSUI, E. Avaliação da proporção de gramínea e leguminosa na dieta de bovinos por determinação de isotópos estáveis de carbono nas fezes. Zootecnia, v. 19, p. 5-15, 1981.

MALAFAIA, P.A.M.; VALADARES FILHO, S.C.; VIEIRA, R.A. et al. Determinação da cinética ruminal das frações protéicas de alguns alimentos para ruminantes. Revista Brasileira de Zootecnia, v.26, n.6, p.1243-1251, 1997.

MANELLA, M.Q.; LOURENÇO, A.J.; LEME, P.R. Recria de Bovinos Nelore em pastos de Brachiaria brizantha com suplementação protéica ou com acesso a banco de proteína de Leucaena lecocephala. Desempenho. Revista Brasileira de Zootecnia, v.31, n.6, p.2274-2282, 2002.

MCCOLLUM, F.T.; GALYEAN, M.L. Influence of cottonseed meal suplementation on voluntary intake, rumen fermentation and rate of passage of praire hay in beef steers. Journal of Animal Science, v.60, p.570-580, 1985.

MILTON, C.T.; BRANDT JR, R.T. Level of urea in high grain diets: digestibility, microbial protein production, and rumen metabolism. Cattle feeders Day Program, report 704, p.4-6, 1994.

MINSON, D.J. Forage in ruminant nutrition. San Diego: Academic Press, Inc., 1990. 483p.

MOSS, R.J.; MURRAY, R.M. Rearing dairy calves on irrigated tropical pastures. I. Effect of protein level on liveweight gain and blood components. Australian Journal of Experimental Agriculture, v.32, p.569-579, 1992.

MULLIK, M.L.; POPPI; D.P.; MCLENNEN, S.R. Increasing growth rates of cattle in the wet season using supplements of molasse/urea combined with various protein sources. Animal Production in Australia, v.22, p.314, 1998.

NOCEK, J.E.; RUSSELL, J.B. Protein and energy as an integrated system. Relationship of ruminal protein and carbohydrate avilability to microbial sinthesis and milk production.Journal of Dairy Science, v.71, p.2070-2107, 1988.

OLSON, K.C.; COCHRAN, R.C.; JONES, T.J. et al. Effects of ruminal administration of degradable intake protein and starch on utilization of low quality warm season grass hay by beef steers. Journal of Animal Science, v.77, p.1016-1025, 1999.

PETIT, H.V.; FLIPOT, P.M. Feed utilization of beef steers fed grass as hay or silage with or without nitrogen supplementation. Journal of Animal Science, v.70, p.876-883, 1992.

PITTS, J. S.; MCCOLluM, F.T.; BRITTON, C.M. Protein supplementationof steers grazing tobosa-grass in spring and summer. Journal of Range Management, v.45, p.226-231, 1992.

POPPI, D.P.; McLENNAN, S.R. Protein and energy utilization by ruminnts at pasture. Journal of Animal Science, v.73, n.1, p.278-290, 1995.

PRIOR, S.J.; POPPI, D.P.; McLENNAN, S.R. Microbial protein production in cattle fed ryegrass, buffel grass and spear grass hays. Animal Production in Australia, v.22, p.315, 1998.

REID, C.W.S.; ULYATT, M.J.; WILSON, J.H. Plant tannins, bloat and nutritive value. Proceedings of the New Zealand Society of Animal Production, v.34, p.82-92, 1974.

ROBERTSON, J.B., VAN SOEST, P.J. The detergent system of analysis and its application to human foods. In: JAMES, W.P.T.; THEANDER, O. (Eds.) The analysis of dietary fiber in food. New York: Marcel Dekker, 1981. p.123-158.

RUSSELL, J. =B. Minimização das perdas de nitrogênio pelos ruminates. In: REUNIÃO ANUAL DA SOCIEDADE BRASILEIRA DE ZOOTECNIA, 34., 1992, Lavras. Anais... Lavras, 1992. p.232.

SAS INSTITUTE SAS User's guides: statistics. 5.ed. Cary: 1985.

SATTER, L.D.; ROFFLER, R.E. Nitrogen requeriment and and utilization in dairy cattle. Journal of Dairy Science, v.58, p.1212-1237, 1979.

SIMPSON, R.B.; CHASE JR., C.C.; HAMMOND, A.C. et al. Average daily gain, blood metabolites, and body composition at first conception in hereford, senepol, and reciprocal crossbred heifers on two levels of winter nutrition and two summer grazing treatments. Journal of Animal Science, v.76, p.396-403, 1999.

SHAIN, D.H.; STOCK, R.A.; KLOPFENSTEIN, T.J. et al. Effect of dgradable intake protein level on finishing cattle performance and ruminal metabolism. Journal of Animal Science, v.76, p. 242-248, 1998.

SLYTER, L.L.; SATTER, L.D.; DINIUS, D.A. Effect of ruminal concentration on nitrogen utilization by steers. Journal of Animal Science, v.48, n.4, p.906-912, 1979.

TILEY, J.M.A.; TERRY, R.A. Two-stage techinique for the in vitro digestion of forage crop. Journal the British Grassland Society, v.18, p.104-11, 1963.

VALADARES, R.F.D.; GONÇALVES, L.C.; RODRIGUEZ, N.M. et al. Níveis de proteína em dietas de bovinos. 4. Concentrações de amônia ruminal e uréia plasmática e excreções de uréia e creatinina. Revista da Sociedade Brasileira de Zootecnia, v.26, p.1270-1278, 1997.

WHITELAW, F.G.; EADIE, J.; BRUCE, L.A. et al. Methane formation in faunated and ciliated-free cattle and its relationship with rumen volatile fatty acid proportions. British Journal of Nutrition, v.52, p.261-275, 1984.

ZEOULA, L.M.; PRADO, I.N.; CECATO, U. et al. Valor nutritivo de rações compostas de fontes de amido e de nitrogênio com alta e baixa degradabilidade ruminal. Revista da Sociedade Brazileira de Zootecnia, v.28, n.5, p.1159-1167, 1999.

R. Bras. Zootec., v.32, n.4, p.1002-1012, 2003

Recebido em: 09/04/02

Aceito em: 16/01/03 